\title{
Biology and Fertility Life Table of Aganaspis pelleranoi (Hymenoptera: Figitidae) in Larvae of Anastrepha fraterculus and Ceratitis capitata (Diptera: Tephritidae)
}

\author{
R. S. GONÇALVES, ${ }^{1}$ D. E. NAVA, ${ }^{2,3}$ H. C. PEREIRA, ${ }^{1}$ H. LISBÔA, ${ }^{1}$ A. D. GRÜTZMACHER, ${ }^{1}$ \\ AND R. A. VALGAS ${ }^{2}$
}

AQ:1-2

Ann. Entomol. Soc. Am. 106(6): 000-000 (2013); DOI: http://dx.doi.org/10.1603/AN13044

\begin{abstract}
Aganaspis pelleranoi (Brèthes) (Hymenoptera: Figitidae) is an important fruit fly parasitoid native to the Neotropics. We investigated the biology and constructed a fertility life table for A. pelleranoi reared on larvae of Anastrepha fraterculus (Wiedemann) and Ceratitis capitata (Wiedemann) (Diptera: Tephritidae). Parasitoid development was investigated in larvae of the two fruit fly species by recording the duration of the egg-adult period, number of offspring, sex ratio, adult weight, adult hind tibia length, and male and female longevity, and constructing a fertility life table. Parasitoids reared on An. fraterculus larvae produced more offspring, had shorter egg-adult periods, greater proportion of females and longer survival, and higher percent emergence than parasitoids reared on C. capitata larvae. Moreover, A. pelleranoi individuals reared on An. fraterculus larvae were heavier and had longer hind tibia than those reared on C. capitata. Based on life table statistics, the time required to double the population $\left(\mathrm{T}_{\mathrm{d}}\right)$ was $\approx 3.4$ times shorter for parasitoids reared on $A n$. fraterculus larvae. Our results show that A. pelleranoi develops better on larvae from An. fraterculus than C. capitata, indicating that this species could be used for the mass production of this parasitoid intended for augmentative biological control of fruit flies.
\end{abstract}

KEY WORDS biological control, fruit fly, parasitoid, parasitism

Fruit flies present a major obstacle for the fruit industry in Brazil, in terms of both direct consumption and export, as several countries restrict importation of fruit from regions where these pests are known to occur (Nascimento and Carvalho 2000). Fruit flies may be controlled using organophosphate and pyrethroid insecticides, applied as full-coverage sprays or through toxic baits (Raga 2005, Härter et al. 2010). However, given the problems caused by pesticide overuse (Norris et al. 2002), integrated pest management (IPM) programs for fruit production have encouraged the use of different control strategies, such as biological control, the sterile insect technique (Kamiya 2010), and bagging fruits in small areas (Nava and Botton 2010). This last is one of the most promising methods for controlling insect pests on fruit trees, and in recent decades, there has been a remarkable resurgence in its use for managing pest tephritids (Ovruski et al. 2003).

Among the many natural threats to fruit flies in Brazil, hymenopteran parasitoids are among the most important and are present in different agroecosystems. Several faunistic surveys show that Doryctobra-

${ }^{1}$ Departamento de Fitossanidade, FAEM/UFPel, 96010-900 Pelo- con areolatus (Szépligeti) (Hymenoptera: Braconidae) is the most frequent species parasitizing larvae of Anastrepha spp. and Ceratitis capitata (Wiedemann) (Diptera: Tephritidae) (López et al. 1999, Canal and Zucchi 2000, Nunes et al. 2012). The solitary koinobiont endoparasitoid Aganaspis pelleranoi (Brèthes) (Hymenoptera: Figitidae) also has been frequently found in commercial orchards and areas with native fruit trees in many countries (Salles 1996, Garcia and Corseuil 2004, Schliserman et al. 2010, Nunes et al. 2012). Females of this species mainly attack larvae in fallen fruits, entering the fruits through existing holes (Ovruski et al. 2006). While studying the development of immatures of A. pelleranoi using C. capitata and Anastrepha spp. as hosts, Ovruski (1994) found that the larvae pass through four stages, followed by the prepupa and pupa development. In addition to sharing the same host species with $D$. areolatus, this Neotropical hymenopteran has been found parasitizing species from the family Lonchaeidae in Brazil (Guimarães et al. 1999). Faunistic surveys show that A. pelleranoi occurs in all Brazilian regions (Guimarães et al. 2000), parasitizing $26-89.6 \%$ of its hosts, depending on the species and crop (Garcia and Corseuil 2004, Souza et al. 2005, Nunes et al. 2012).

Historically, biological control of fruit flies in Brazil began in 1937 with the introduction of Tetrastichus giffardianus (Silvestri) (Hymenoptera: Eulophidae) 
for the control of C. capitata (Autuori 1938); however, surveys conducted after the release did not find the species (Costa et al. 2005). In 1994, Diachasmimorpha longicaudata (Ashmead) (Hymenoptera: Braconidae) was introduced as a biological control agent against various fruit fly species, but the rate of parasitism did not exceed $12 \%$ (Carvalho and Nascimento 2002). The failure of $T$. giffardianus and D. longicaudata to become established is probably related to adverse climate conditions for the parasitoids (Nava 2007). Even though classical biological control is a viable option for managing insect pests, it has proven unsuccessful with fruit flies. One alternative is to use native parasitoids in inundative biological control programs, although little is known about natural biological control and the potential of native parasitoids in Brazil. In the case of A. pelleranoi, a few studies of its biology have been conducted in Mexico and Argentina (Ovruski 1994 Aluja et al. 2008, Cancino et al. 2008), while in Brazil most studies have focused on its taxonomy (Canal and Zucchi 2000, Guimarães et al. 2000), behavior (Guimarães and Zucchi 2004), distribution, occurrence, and tritrophic interactions (Matrangolo et al. 1998, Guimarães et al. 1999, Alvarenga et al. 2009). The aim of this study was to investigate the biology and construct a fertility life table of A. pelleranoi on Anastrepha fraterculus (Wiedemann) and C. capitata larvae reared on artificial diets, to support biological control programs against fruit flies.

\section{Materials and Methods}

Rearing of An. fraterculus, C. capitata, and A. pelleranoi and experiments on their biology were conducted in climatized rooms (under the following conditions: $25 \pm 2^{\circ} \mathrm{C}, 70 \pm 10 \%$ relative humidity [RH] and a photoperiod of 12:12 [L:D] h), in the entomology laboratory of the Empresa Brasileira de Pesquisa Agropecuária de Clima Temperado.

Rearing Methods. An. fraterculus puparia (50th generation) were obtained from the Laboratory of Food Irradiation and Radioentomology at the Center for Nuclear Energy in Agriculture-University of São Paulo (CENA-USP). Adults were kept in plastic cages measuring 57 by 39 by $37 \mathrm{~cm}$ (l by w by h), and fed a solid diet of refined sugar, wheat germ, and yeast extract (Bionis YE MF, Biorigin, Lençois Paulista, São Paulo, Brazil), 3:1:1, respectively, supplied in Gerboxtype plastic containers measuring 11.5 by 11.5 by 3.5 cm (l by w by h; Gerbox, J. Prolab Ltda, São José dos Pinhais, Paraná, Brazil; Nunes 2010). Refined sugar was also provided in a petri dish of $9 \mathrm{~cm}$ in diameter and $1.5 \mathrm{~cm}$ in height, during the first week after emergence. In addition to rations, water was supplied from a 250 -ml bottle by capillary action through a strip of vegetable sponge cloth (Spontex, Ilhéus, Bahia, Brazil) inside the cage.

Eggs were obtained by placing a red silicone "voile" cloth $(43 \mathrm{~cm}$ in length by $27 \mathrm{~cm}$ in width; Corttex, Corttex, Três Lagoas, Minas Gerais, Brazil) on one side of the adults' cages. A thin layer of silicone $(1 \mathrm{~mm})$ was spread evenly on the cloth, using a small piece of cardboard. To maintain the humidity inside the cage and prevent egg dehydration, a plastic tray with a moistened layer of cotton and vegetable sponge cloth was placed over the egg-laying substrate. Females were attracted to the cloth oviposition substrate with fluorescent lamps ( $360 \mathrm{~nm}$ and 40 watts; Walder 2002).

The eggs were removed with water jets every $24 \mathrm{~h}$ and placed in a plastic tray. Then, the eggs were transferred to a 500-ml Erlenmeyer flask and aerated for $24 \mathrm{~h}$ using a tank aerator (Kamiya 2010). After that period, the eggs were given artificial diet for larval development on a strip of filter paper. In total, $300 \mathrm{ml}$ of ration was used for each $0.7 \mathrm{ml}$ of eggs $(\approx 8,190$ eggs). The diet used for larval development and the preparation methods were described by Salles (1992); we only increased the amount of agar added, from 10 to $3.6 \mathrm{~g}$ (Nunes 2010). For pupariation, the diet was removed in the late third-instar stage by collecting the larvae, using a sieve under running water, and placing them $(\approx 4,000$ insects $)$ in trays (Sanremo, Bettanin Industrial S/A, Esteio, Rio Grande do Sul, Brazil) measuring 20 by 25 by $7.5 \mathrm{~cm}$ (l by w by h), with moistened fine vermiculite, where they were kept until emergence.

C. capitata. The culture was established with $C$. capitata puparia (60th generation) from the Laboratory of Food Irradiation and Radioentomology at CENA-USP. Adults were kept in plastic cages measuring 40 by 30 by $30 \mathrm{~cm}$ (l by w by h), with water and ration, as described for An. fraterculus. Eggs were obtained by placing white voile cloth on one side of the cage, on which females exposed their ovipositor and laid eggs, which then dropped into a tray with a shallow layer of distilled water. Fluorescent lamps placed near the cloth attracted females to oviposit on the cloth. Eggs of C. capitata were collected and aerated as described for An. fraterculus. For larval development, $\approx 0.65 \mathrm{ml}$ of eggs $(\approx 15,000$ eggs $)$ were placed on filter paper in a plastic container measuring 28 by 17.2 by $8 \mathrm{~cm}$ (l by w by h; Sanremo, Bettanin Industrial S/A), with 300 $\mathrm{ml}$ artificial diet. The larval diet and collection procedure were the same as described for An. fraterculus.

A. pelleranoi. For rearing A. pelleranoi, araçá fruit [(Psidium cattleianum Sabine, 1821) (Myrtaceae)] infested with An. fraterculus was collected from native fruit orchards at Embrapa Temperate Climate, Pelotas, Rio Grande do Sul, Brazil. Next, the fruit was taken to the laboratory and placed in plastic trays (19 by 13.5 by $3.5 \mathrm{~cm}$ [l by w by h]), with a 3 -cm layer of fine vermiculite covered with voile.

The vermiculite was sifted daily for a week during egression of the fruit fly larvae from the fruit. Puparia collected were transferred to plastic boxes measuring 11 by 11 by $3.5 \mathrm{~cm}$ (l by w by h; Gerbox) with moistened fine vermiculite, where they were kept inside emergence cages measuring 40 by 30 by $30 \mathrm{~cm}$ (l by w by $\mathrm{h}$ ). After emergence, A. pelleranoi individuals were removed and placed in specific cages ( 17.7 by 26.2 by $14.7 \mathrm{~cm}$ [l by w by h]) for rearing adults. A 50 -ml water bottle supplied by capillary action through a strip of vegetable sponge cloth (Spontex) was placed inside each cage. Parasitoids were fed a 
$30 \%$ honey aqueous solution absorbed in a vegetable sponge cloth placed in a petri dish $(3 \mathrm{~cm}$ in diameter by $1.5 \mathrm{~cm}$ in height). Third-instar fruit flies were given $(\approx 200$ larvae $)$ to parasitoids in acrylic plates $(4 \mathrm{~cm}$ in diameter by $0.2 \mathrm{~cm}$ in height) wrapped in voile placed at the bottom of the parasitoid cages. The larvae were exposed to parasitism for $4 \mathrm{~h}$.

A portion of the adults that emerged from field collections were stored in 5-ml plastic cups with $70 \%$ ethyl alcohol and identified by Valmir Antônio Costa at the Biological Institute of São Paulo Agency for Agribusiness Technology, Campinas, São Paulo, Brazil. Part of the identified specimens have been stored in the Entomological Collection at the company Embrapa Clima Temperado, Pelotas, Rio Grande do Sul, Brazil.

Biology of A. pelleranoi. In total, 50 A. pelleranoi couples reared from An. fraterculus and C. capitata larvae ( 25 couples each) were paired for $24 \mathrm{~h}$ after emergence. The insects were sexed based on morphological characters of the antennae; males have longer antennae than females (Guimarães et al. 2000). The couples were paired (one couple per plastic cup) in 300-ml plastic cups covered with voile for aeration.

Parasitoids were fed a $30 \%$ honey aqueous solution absorbed in toilet paper, forming a paste mixture provided in acrylic plates $(2.2 \mathrm{~cm}$ in diameter by $0.6 \mathrm{~cm}$ in height). Each couple was given 15 third-instars daily until the death of the females. The larvae were placed in acrylic plates $(1.7 \mathrm{~cm}$ in diameter by $0.1 \mathrm{~cm}$ in height) wrapped in voile, and fed artificial diets. After $4 \mathrm{~h}$ exposure, larvae were placed in acrylic containers ( $2.5 \mathrm{~cm}$ in diameter by $4.5 \mathrm{~cm}$ in height) with moistened extra-fine vermiculite, where they were kept until emergence of flies, parasitoids, or both. The number of emerged flies and parasitoids was recorded for $\approx 20 \mathrm{~d}$ after exposure. Next, any remaining intact puparia were dissected, and the presence of flies or parasitoids was recorded to determine the actual parasitism rates.

The following parameters were determined for the parasitoids: weight and hind tibia length of newly emerged adults, duration of egg-adult period, sex ratio (SR), male and female longevity, number of offspring (NO), and percent emergence (E). SR was determined by the following equation: $\mathrm{SR}=$ (number of females)/NO. The SR value ranges from 0 to 1 , indicating that females outnumber males when the value is closer to 1 , and males outnumber females when the value is closer to 0 . NO was determined by the following equation: $\mathrm{NO}=$ number of emerged parasitoids + number of nonemerged parasitoids.

After emergence, the adults of A. pelleranoi were killed with ether and then weighed on an Ohaus ExAQ:5 plorer SQ17 precision balance $(0.0001 \mathrm{mg})$. The length of the posterior tibia was measured under a stereoscopic microscope (Zeiss Stemi SV11, Zeiss, Jena, Germany) with an ocular graded in micrometers, AQ: 6 at $5 \times$ magnification. The longevity and fecundity of adults were recorded daily and the following fertility life table parameters were calculated: generation time $(T)$, doubling time $\left(T_{d}\right)$, net reproductive rate $\left(R_{o}\right)$,
Table 1. Mean values $( \pm \mathrm{SE})$ for number of offspring, sex ratio, emergence, length of tibia of males and females, and weight of adult males and females of A. pelleranoi reared on An. fraterculus and C. capitata larvae

\begin{tabular}{|c|c|c|c|c|}
\hline \multirow{2}{*}{$\begin{array}{l}\text { Biological } \\
\text { parameter }\end{array}$} & \multicolumn{2}{|c|}{ Host } & \multirow{2}{*}{$\mathrm{df}$} & \\
\hline & An. fraterculus & C. capitata & & \\
\hline No. of off & $96.1 \pm 3.05 \mathrm{a}$ & $14.4 \pm 1$ & 1 & $<0.0001$ \\
\hline Sex rati & 0 & & 1 & - \\
\hline Emergence (\%) & $88.30 \pm 5.45 \mathrm{a}$ & $67.30 \pm$ & 1 & 0.00 \\
\hline \multicolumn{5}{|c|}{ Hind tibia length } \\
\hline Males (mm) & $1.041 \pm 0.0069 \mathrm{a}$ & $0.866=$ & 1 & $<0.0001$ \\
\hline Females (mm) & $1.043 \pm 0.0048 \mathrm{a}$ & $0.900 \pm$ & 1 & $<0.0001$ \\
\hline \multicolumn{5}{|l|}{ Adult wt } \\
\hline Males (mg) & $0.88 \pm 0.038 \mathrm{a}$ & $0.53 \pm 0.025 \mathrm{~b}$ & 1 & $<0.0001$ \\
\hline Females (mg) & $1.00 \pm 0.038 \mathrm{a}$ & $0.70 \pm 0.047 \mathrm{~b}$ & 1 & $<0.001$ \\
\hline
\end{tabular}

Temperature: $25 \pm 2^{\circ} \mathrm{C}$; $\mathrm{RH}: 70 \pm 10 \%$; a photoperiod of $12: 12$ (L:D) h.

intrinsic rate of increase $\left(\mathrm{r}_{\mathrm{m}}\right)$, and finite rate of increase $(\lambda)$. To determine the size difference between the two fruit fly species, 100 pupae of each species were measured in milligrams, with a precision of $0.0001 \mathrm{mg}$ (Ohaus Explorer SQ17).

Statistical Analysis. The experiment was conducted in a fully randomized design with two treatments (hosts) and 25 replicates, each consisting of a parasitoid couple. Data for the weight of adults, posterior tibia length, egg-adult period of A. pelleranoi, and pupal weight of C. capitata (mean weight: $7.37 \mathrm{mg}$ ) and An. fraterculus (mean weight: $12.12 \mathrm{mg}$ ) were evaluated for normality by the Harley test and for homoscedasticity by the Shapiro-Wilks test. The data were then analyzed by analysis of variance (ANOVA) using the GLM procedure of the SAS software (SAS Institute 9.22002 ), and the means were compared by $t$-test at the $5 \%$ significance level.

Data on NO were analyzed using generalized linear models with the GENMOD procedure (SAS Institute 9.22002 ), and means were compared with the $\chi^{2}$ test at $P<0.05$. To analyze the SR, the mean proportions for each treatment were compared with the $\mathrm{Z}$ test $(P<0.05)$ and $\chi^{2}$ test $(P<0.05)$, which was carried out considering the observed frequencies of females relative to the observed frequency of the entire population (males + females) using the $\mathrm{R}$ software ( $\mathrm{R}$ Development Core Team 2009).

To evaluate adult longevity, survival curves were constructed using the Kaplan-Meier method and were compared with the log-rank test in the $\mathrm{R}$ software ( $\mathrm{R}$ Development Core Team 2009). Fertility life table parameters and the respective SEs were calculated, and means were compared with a two-tailed $t$-test $(P<0.05)$ using the "Lifetable.sas" programming (Maia et al. 2000) in the SAS software (SAS Institute $9.22002)$.

\section{Results and Discussion}

A. pelleranoi females reared on An. fraterculus larvae produced 96.1 offspring on average during their lives, whereas females reared on C. capitata larvae generated only 14.4 offspring (Table 1 ). These figures are 


\begin{tabular}{|l|l|l|l|l|l|l|}
\hline rich3/zan-ann-ent/zan-ann-ent/zan00613/zan7188d13z & xppws & $\mathrm{S}=1$ & $10 / 4 / 13$ & $3: 31$ & Art: AN-13-044 & 1st disk, 2nd mo \\
\hline
\end{tabular}

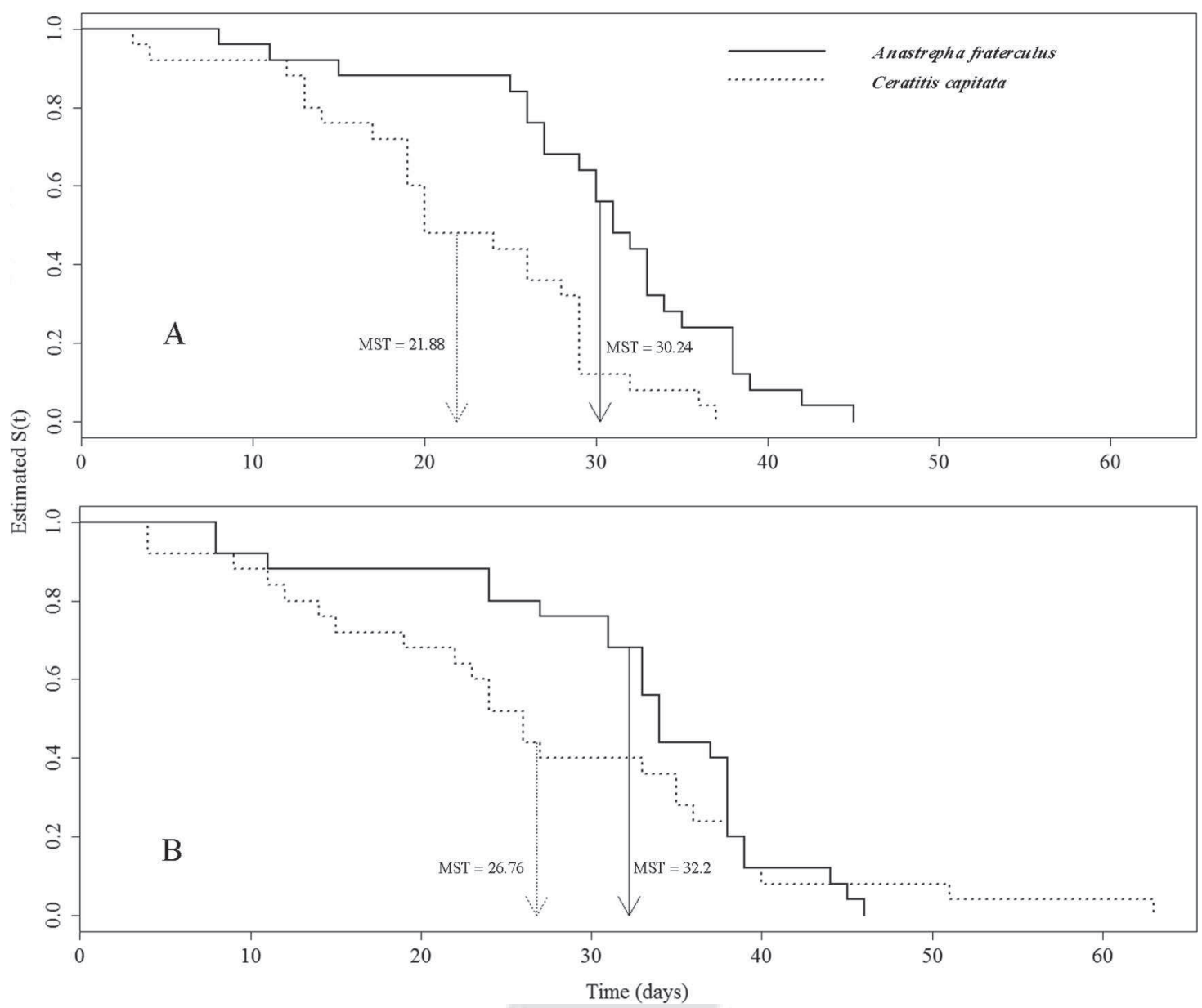

Fig. 1. Survival curves of female (A) and male (B) adults of A. pelleranoi reared on An. fraterculus and C. capitata larvae. Temperature: $25 \pm 2^{\circ} \mathrm{C}$; RH: $70 \pm 10 \%$; a photoperiod of 12:12 (L:D) h. Curves in (A) are significantly different $(P<0.05)$ whereas in (B) they are not. The arrows indicate mean survival time (MST).

higher than the 5.17 offspring per female reported by Aluja et al. (2008), rearing A. pelleranoi on Anastrepha ludens (Loew) (Diptera: Tephritidae) larvae.

The SR of emerged parasitoids was significantly higher in individuals reared on An. fraterculus (0.402) than C. capitata (0.187) larvae (Table 1). Aluja et al. (2008) found variations in SR between generations ranging from 0.2 to 0.8 when rearing A. pelleranoi on An. ludens larvae. However, in an experiment on pupae irradiation, Cancino et al. (2008) found an SR of 2.67 (females per male) in the control treatment (without irradiation). Ovruski et al. (2011) reported that D. longicaudata populations reared on An. fraterculus larvae had a higher percentage of females $(79.5 \%)$ than those reared on C. capitata larvae $(55.0 \%)$, and they attributed this result to the difference in the size of the hosts. These results show that the number of female parasitoids is higher in larvae of Anastrepha species, a difference which is likely related to host size. There is a tendency in solitary parasitoids to lay eggs that produce males on small hosts and females on larger hosts (Godfray 1995, Sagarra et al. 2001). However, the result of our study can also be explained because of chemical differences between

Table 2. Mean values $( \pm S E)$ for generation time $(T)$, doubling time $\left(T_{d}\right)$, net reproductive rate $\left(R_{o}\right)$, intrinsic rate of increase $\left(r_{m}\right)$, and finite rate of increase $(\lambda)$ of $A$. pelleranoi reared on An. fraterculus and $C$. capitata larvae

\begin{tabular}{lcrrrr}
\hline \hline \multicolumn{1}{c}{ Host } & $\mathrm{T}(\mathrm{d})$ & \multicolumn{1}{c}{$\mathrm{T}_{\mathrm{d}}(\mathrm{d})$} & $\mathrm{R}_{\mathrm{o}}$ & $\mathrm{r}_{\mathrm{m}}$ & $\lambda$ \\
\hline An. fraterculus & $38.98 \pm 0.35 \mathrm{~b}$ & $8.25 \pm 0.35 \mathrm{~b}$ & $26.0 \pm 3.61 \mathrm{a}$ & $0.0838 \pm 0.0036 \mathrm{a}$ & $1.0875 \pm 0.0038 \mathrm{a}$ \\
C. capitata & $40.78 \pm 6.15 \mathrm{a}$ & $27.61 \pm 6.15 \mathrm{a}$ & $2.60 \pm 0.48 \mathrm{~b}$ & $0.0240 \pm 0.0046 \mathrm{~b}$ & $1.0243 \pm 0.0047 \mathrm{~b}$ \\
\hline
\end{tabular}

Temperature: $25 \pm 2^{\circ} \mathrm{C}$; RH: $70 \pm 10 \%$; a photoperiod of 12:12 (L:D) h

Means within a column followed by the same letter are not significantly different for the two-tailed Student $t$-test $(P<0.05)$. 


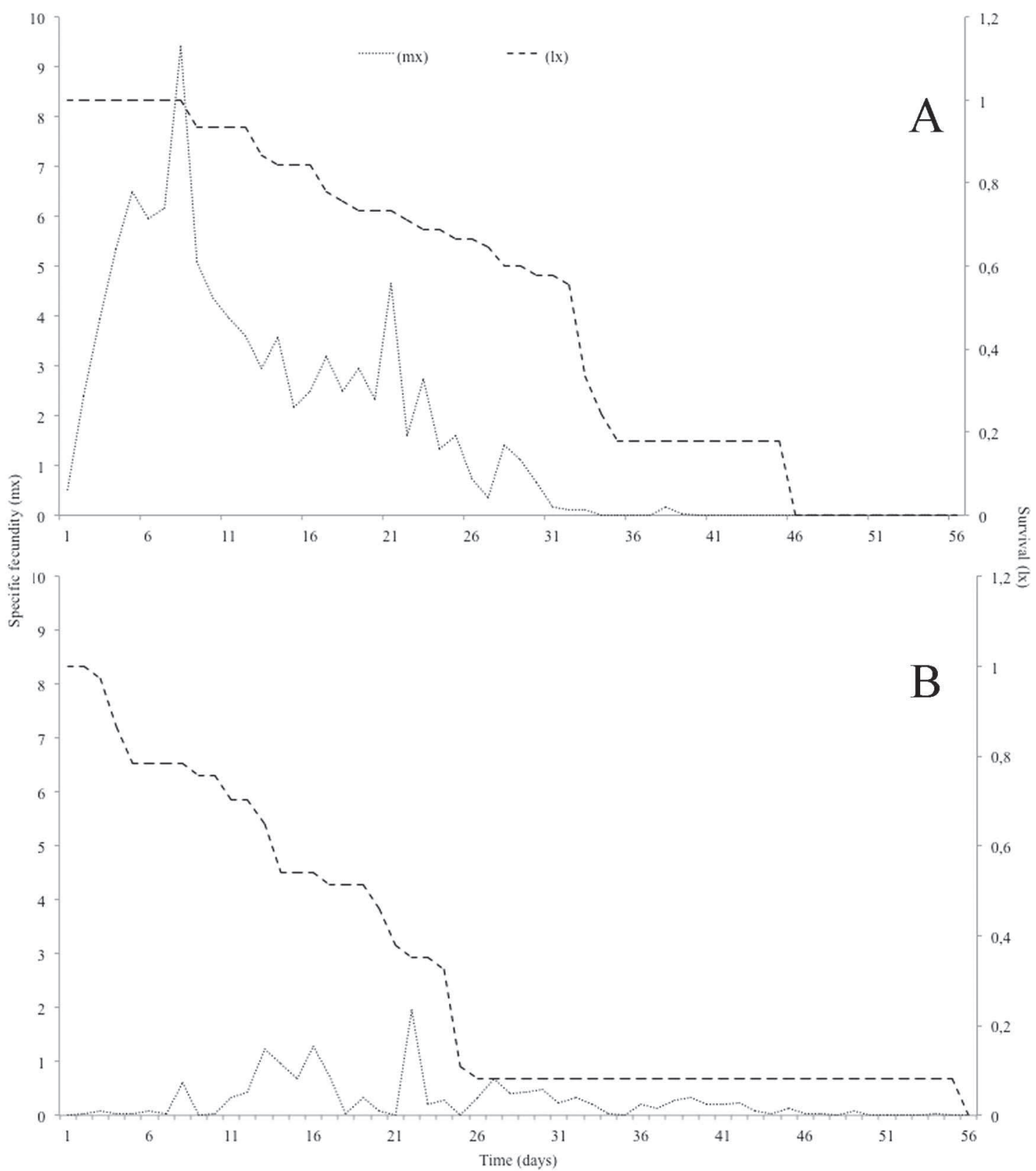

Fig. 2. Relationship between age-specific fecundity $(\mathrm{mx})$ and age-specific survival (lx) of A. pelleranoi reared on $\mathrm{An}$. fraterculus (A) and C. capitata (B) larvae. Temperature: $25 \pm 2{ }^{\circ} \mathrm{C}$; RH: $70 \pm 10 \%$; a photoperiod of 12:12 (L:D) h.

the hosts. This was previously reported by Eben et al. (2000), who found a larger number of females from An. ludens larvae for D. longicaudata than for Anastrepha obliqua larvae (Macquart, 1835) (Diptera: Tephritidae).

A significant difference in longevity was observed between females reared on An. fraterculus and C. capitata larvae $\left(\chi^{2}=12.3 ; \mathrm{df}=1 ; P=0.000445 ;\right.$ Fig. $\left.1 \mathrm{~A}\right)$ but no differences were observed between male individuals $\left(\chi^{2}=0.6\right.$; $\mathrm{df}=1 ; P=0.456$; Fig. 1B). Mean survival durations for both female and male adults of A. pelleranoi were longer in individuals reared on larvae of An. fraterculus (30.24 \pm 0.07 and $32.2 \pm 0.09 \mathrm{~d}$, respectively) than on larvae of C. capitata (21.88 \pm 0.08 and $26.76 \pm 0.06 \mathrm{~d}$, respectively; Fig. 1).

López et al. (2009) observed that longevity of $D$. longicaudata females reared on different-sized $A n$. ludens larvae was affected by host size only when the females were fasted. The authors also observed that females reared on medium $(2.43 \mathrm{~mm})$ and large $(2.84$ 
mm) An. ludens larvae survived longer than females reared on small larvae $(2.2 \mathrm{~mm})$. Nevertheless, the highest longevity for fed females was observed in those reared on medium-sized larvae (20.13 d), while for males the highest longevity ( $16.41 \mathrm{~d}$ ) was recorded in individuals reared on large larvae $(2.84 \mathrm{~mm})$.

Several studies have shown a strong relationship between host size and parasitoid survival (Tillman and Cate 1993, Sagarra et al. 2001). This relationship can be explained by the greater nutrient availability in large hosts (Rivero and West 2002, Ellers and Jervis 2003). This may also be the case for A. pelleranoi, because An. fraterculus puparia were heavier compared with $C$. capitata puparia and produced male and female individuals with significantly longer mean hind tibia (Table 1). Although the puparia of An. fraterculus weigh more than those of C. capitata, it is necessary to consider that this is a variable characteristic and can change according to the insects' diet. Therefore, in our study the larvae of both species were fed the same diet, and for this reason we believe that the greater longevity of adults of A. pelleranoi originating from larvae of An. fraterculus is a consequence of the better conditions afforded by this host. Significant differences were also recorded for adult weight: male and female individuals of A. pelleranoi reared on An. fraterculus larvae were heavier on average than individuals reared on C. capitata (Table 1). This difference is highly important for the process of the choice of a host to use in biological control programs, as, according to Lawrence et al. (1976), the size of the parasitoid can influence the efficiency of the search for a host under field conditions.

Fertility life table statistics show that the mean $\mathrm{T}$ of A. pelleranoi reared on An. fraterculus larvae is $\approx 2 \mathrm{~d}$ shorter than for parasitoids reared on C. capitata larvae (Table 2). The values for $T_{d}, R_{o}, r_{m}$, and $\lambda$ were significantly higher for parasitoids reared on $A n$. fraterculus larvae than for those on C. capitata. The $\mathrm{R}_{\mathrm{o}}$ of the parasitoids developed on larvae of An. fraterculus indicates its capacity to increase its population 10 -fold more, in one generation, than on larvae of $C$. capitata. Some parameters found in this study are close to those observed by Aluja et al. (2008). The authors reported an $R_{o}$ of 2.84 for $A$. pelleranoi reared on $A n$. ludens larvae, which is similar to the value recorded in this study (2.60) for parasitoids reared on C. capitata larvae. The same authors reported higher $r_{m}$ and $\lambda$ values ( 0.13 and 1.15 , respectively) than those reported in this study for A. pelleranoi reared on either An. fraterculus or C. capitata larvae (Table 2). The maximum rate of increase of $A$. pelleranoi populations reared on An. fraterculus and C. capitata larvae was recorded on days 8 and 22 , respectively (Fig. 2 ). This difference in the occurrence of the maximum rate may result from a nutritional advantage of A. pellerani females from An. fraterculus during their preimaginal development, although after emergence, the females from both hosts were fed with the same diet.

Several studies with A. pelleranoi populations show that this parasitoid species is often found on C. capitata larvae (Ovruski 1995, Wharton et al. 1998, Ovruski et al. 2004). However, the difference observed in this study, according to them, could be related to the possible existence of variability between the A. pelleranoi populations. Another likely explanation of the better performance of A. pelleranoi when reared on An. fraterculus larvae may be the long coevolutionary history of the two species, as both are native to the Neotropics. Unlike the South American fruit fly, C. capitata is an exotic species to Brazil, which was introduced in 1901 (von Ihering 1901). Therefore, the ecological relationship between $A$. pelleranoi and $C$. capitata is still quite recent compared with An. fraterculus and the parasitoid species. The South American fruit fly may have developed specific physiological mechanisms to combat the parasitoid, which C. capitata lacks. Nevertheless, in the course of the coevolutionary process, probably A. pelleranoi was also capable of developing mechanisms to overcome the defenses of An. fraterculus larvae.

The results showed that A. pelleranoi performed better when reared on An. fraterculus larvae, and indicate that this species is the most suitable for massrearing of the parasitoid in the laboratory. This parasitoid can be mass-produced by using the larvae of $A n$. fraterculus as the production host, and this host should be used for augmentation biological programs to control fruit flies. However, studies will be necessary to assess the effect of rearing during many generations under mass-production conditions. Under these conditions, there will always be the possibility of a loss of performance by the parasitoid population.

\section{Acknowledgments}

We thank Professor Júlio Marcos Melges Walder and biologist Maria de Lourdes Zamboni Costa at CENA-USP for making fruit flies available. We also thank the National Council for Scientific and Technological Development (CNPq) for financial support for part of the study and research scholarships for the second author, and to Janet Reid (JWR ASSOCIATES) for the English revisions.

\section{References Cited}

Aluja, M., J. Sivinski, S. Ovruski, L. Guillen, M. Lopez, J. Cancino, A. Torres-Anaya, G. Gallegos-Chan, and L. Ruiz. 2008. Colonization and domestication of seven species of native New World hymenopterous larvalprepupal and pupal fruit fly (Diptera: Tephritidae) parasitoids. Biocontrol Sci. Technol. 19: 49-79.

Alvarenga, C. D., C.A.R. Matrangolo, G. N. Lopes, M. A. Silva, E. N. Lopes, D. A. Alves, A. S. Nascimento, and R. A. Zucchi. 2009. Moscas-das-frutas (Diptera: Tephritidae) e seus parasitoides em plantas hospedeiras de três municípios do norte do estado de Minas Gerais. Arquivos Do Instituto Biologico 76: 195-204.

Autuori, M. 1938. Notas sobre a introdução e multiplicação do parasita Tetrastichus giffardianus Silv. no Brasil. O Biológico 6: 345-351.

Canal, N. A., and R. A. Zucchi. 2000. Parasitóides-Braconidae, pp. 119-126. In A. Malavasi and R. A. Zucchi (eds.), Moscas-das-Frutas de Importância Econômica no Brasil: Conhecimento Básico e Aplicado. Holos, Ribeirão Preto, SP, Brazil.

\section{AQ: 8}


\begin{tabular}{|l|l|l|l|l|l|l|}
\hline rich3/zan-ann-ent/zan-ann-ent/zan00613/zan7188d13z & xppws & $\mathrm{S}=1$ & $10 / 4 / 13$ & $3: 31$ & Art: AN-13-044 & 1st disk, 2nd mo \\
\hline
\end{tabular}

November 2013

Gonçalves et al.: Biology and Fertility Life Table of A. pelleranoi

Cancino, J., L. Ruiz, J. Sivinski, F. Galvez, and M. Aluja. 2008. Rearing of five hymenopterous larval-prepupal (Braconidae, Figitidae) and three pupal (Diapriidae, Chalcidoidea, Eurytomidae) native parasitoids of the genus Anastrepha (Diptera: Tephritidae) on irradiated A. ludens larvae and pupae. Biocontrol Sci. Technol. 19: 193-209.

Carvalho, R. S., and A. S. Nascimento. 2002. Criação e utilização de Diachasmimorpha longicaudata para controle biológico de moscas-das-frutas (Tephritidae), pp. 165179. In J.R.P. Parra, P.S.M. Botelho, B. S. Corrêa-Ferreira and J.M.S. Bento (eds.), Controle Biológico no Brasil: Parasitóides e Predadores. Editora Manole, Barueri, SP, Brazil.

Costa, V. A., E. L. Araújo, J. A. Guimarães, A. S. Nascimento, and J. LaSalle. 2005. Redescoberta de Tetrastichus giffardianus (Hymenoptera: Eulophidae) após 60 anos da sua introdução no Brasil. Arquivos Do Instituto Biologico 72: 539-541.

Eben, A., B. Benrey, J. Sivinski, and M. Aluja. 2000. Host species and host plant effects on preference and performance of Diachasmimorpha longicaudata (Hymenoptera: Braconidae). Environ. Entomol. 29: 87-94

Ellers, J., and M. Jervis. 2003. Body size and the timing of egg production in parasitoid wasps. Oikos 102: 164-172.

Garcia, F.R.M., and E. Corseuil. 2004. Native hymenopteran parasitoids associated with fruit flies (Diptera: Tephritidae) in Santa Catarina state, Brazil. Fla. Entomol. 87: 517-521.

Godfray, H.C.J. 1995. Parasitoids: behavioral and evolutionary ecology. Environ. Entomol. 24: 483-484.

Guimarães, J. A., N. B. Diaz, and R. A. Zucchi. 2000. Parasitóide-Figitidae (Eucoilinae), pp. 127-141. In A. Malavasi and R. A. Zucchi (eds.), Moscas-das-Frutas de Importância Econômica no Brasil: Conhecimento Básico e Aplicado. Holos, Ribeirão Preto, SP, Brazil.

Guimarães, J. A., and R. A. Zucchi. 2004. Parasitism behavior of three species of Eucoilinae (Hymenoptera: Cynipoidea: Figitidae) fruit fly parasitoids (Diptera) in Brazil. Neotrop. Entomol. 33: 217-224.

Guimarães, J. A., R. A. Zucchi, N. B. Diaz, M. F. Souza Filho, and M. A. Uchôa, F. 1999. Espécies de Eucoilinae (Hymenoptera: Cynipoidea: Figitidae) parasitóides de larvas frugívoras (Diptera: Tephritidae e Lonchaeidae) no Brasil. Anais da Sociedade Entomológica do Brasil 28: 263273.

Härter, W. R., A. D. Grützmacher, D. E. Nava, R. S. Gonçalves, and M. Botton. 2010. Isca tóxica e disrupção sexual no controle da mosca-da-fruta sul-americana e da mariposa-oriental em pessegueiro. Pesquisa Agropecuária Brasileira 45: 229-235.

von Ihering, H. 1901. Laranjas bichadas. Rev. Agric. 6: 179181.

Kamiya, A. C. 2010. Criação massal em dieta líquida e radioesterilização da mosca-sul-americana Anastrepha sp. 1 aff. fraterculus (Wied., 1830) (Diptera: Tephritidae). Ph.D. dissertation, Universidade de São Paulo, Piracicaba, SP, Brazil.

Lawrence, P. O., R. M. Baranowski, and P. D. Greany. 1976. Effect of host age on development of Biosteres (=Opius) longicaudata, a parasitoid of the Caribbean fruit fly, Anastrepha suspensa. Fla. Entomol. 59: 33-39.

López, M., M. Aluja, and J. Sivinski. 1999. Hymenopterous larval-pupal and pupal parasitoids of Anastrepha flies (Diptera: Tephritidae) in Mexico. Biol. Control 15: 119129.

López, O. P., Y. Hénaut, J. Cancino, M. Lambin, L. CruzLópez, and J. C. Rojas. 2009. Is host size an indicator of quality in the mass-reared parasitoid Diachasmimorpha longicaudata (Hymenoptera: Braconidae)? Fla. Entomol 92: $441-449$

Maia, A.H.N., A.J.B. Luiz, and C. Campanhola. 2000. Statistical inference on associated fertility life parameters using jackknife technique: computational aspects. J. Econ. Entomol. 93: 511-518.

Matrangolo, W.J.R., A. S. Nascimento, R. S. Carvalho, E. D. Melo, and M. Jesus. 1998. Parasitóides de moscas-dasfrutas (Diptera: Tephritidae) associados a fruteiras tropicais. Anais da Sociedade Entomológica do Brasil 27: 593603.

Messing, R. H., L. M. Klungness, M. Purcell, and T.T.Y. Wong. 1993. Quality control parameters of mass-reared opiine parasitoids used in augmentative biological control of tephritid fruit flies in Hawaii. Biol. Control 3: 140-147.

Nascimento, A. S., and R. S. Carvalho. 2000. Manejo integrado de mosca-das-frutas, pp. 169-173. In A. Malavasi and R. A. Zucchi (eds.), Moscas-das-Frutas de Importância Econômica no Brasil: Conhecimento Básico e Aplicado. Holos, Ribeirão Preto, SP, Brazil.

Nava, D. E. 2007. Controle biológico de insetos-praga em frutíferas de clima temperado: uma opção viável, mas desafiadora. Embrapa Clima Temperado, Pelotas, RS, Brazil.

Nava, D. E., and M. Botton. 2010. Bioecologia e controle de Anastrepha fraterculus e Ceratitis capitata em pessegueiro. Embrapa Clima Temperado, Pelotas, RS, Brazil.

Norris, R. F., E. P. Caswell-Chen, and M. Kogan. 2002. Pesticides, pp. 242-313. In R. F. Norris, E. P. Caswell-Chen, and M. Kogan (eds.), Concepts in Integrated Pest Management. Prentice-Hall, Upper Saddle River, NJ.

Nunes, A. M. 2010. Moscas frugívoras (Tephritoidea), seus parasitoides e estudos bioecológicos de Anastrepha fraterculus (Wiedmann, 1830) (Diptera: Tephritidae) e Doryctobracon areolatus (Szépligeti, 1911) (Hymenoptera: Braconidae). M.S. thesis, Universidade Federal de Pelotas, Pelotas, RS, Brazil.

Nunes, A., F. Müller, R. S. Gonçalves, M. Garcia, V. Costa, and D. E. Nava. 2012. Moscas frugívoras e seus parasitoides nos municípios de Pelotas e Capão do Leão, Rio Grande do Sul, Brasil. Ciênc. Rural 42: 6-12.

Ovruski, S. M. 1994. Immature stages of Aganaspis pelleranoi (Brèthes) (Hymenoptera: Cynipoidea: Eucoilidae), a parasitoid of Ceratitits capitata (Wied.) and Anastrepha spp. (Diptera: Tephritidae). J. Hymenopt. Res. 3: 233-239.

Ovruski, S. 1995. Pupal and larval-pupal parasitoids (Hymenoptera) obtained from Anastrepha spp. and Ceratitis capitata (Dipt.: Tephritidae) pupae collected in four localities of Tucuman province, Argentina. BioControl. 40: 367-370.

Ovruski, S. M., L. P. Bezdjian, G. A. Van Nieuwenhove, P. Albornoz-Medina, and P. Schliserman. 2011. Host preference by Diachasmimorpha longicaudata (Hymneoptera: Braconidae) reared on larvae of Anastrepha fraterculus and Ceratitis capitata (Diptera: Tephritidae). Fla. Entomol. 94: 195-200.

Ovruski, S. M., C. Colin, A. Soria, L. E. Oroño, and P. Schliserman. 2003. Introducción y producción en laboratorio de Diachasmimorpha tryonii y Diachasmimorpha longicaudata (Hymenoptera: Braconidae) para el control biológico de Ceratitis capitata (Diptera: Tephritidae) en la Argentina. Revista de la Sociedad Entomológica Argentina 62: 49-59.

Ovruski, S. M., L. E. Oroño, S. Núñes-Campero, P. Schliserman, L. Albornoz-Medina, L. P. Bezdjian, G. A. Van Nieuwenhove, and C. B. Martin. 2006. A review of hymenopterous parasitoid guilds attacking Anastrepha spp. and Ceratitis capitata (Diptera: Tephritidae) in Argen- 
tina, pp. 113-125. In Proceedings of the 7th Internationa Symposium on Fruit Flies of Economic Importance, Salvador, Brazil.

Ovruski, S. M., P. Schliserman, and M. Aluja. 2004. Indigenous parasitoids (Hymenoptera) attacking Anastrepha fraterculus and Ceratitis capitata (Diptera: Tephritidae) in native and exotic host plants in Northwestern Argentina. Biol. Control. 29: 43-57.

Raga, A. 2005. Incidência, monitoramento e controle de moscas-das-frutas na citricultura Paulista. Laranja 26 307-322.

R Development Core Team. 2009. R: a language and environment for statistical computing. $\mathrm{R}$ Foundation for Statistical Computing, Vienna, Austria. (http://www.Rproject.org/)

Rivero, A., and S. A. West. 2002. The physiological costs of being small in a parasitic wasp. Evol. Ecol. Res. 4: 407-420.

Sagarra, L. A., C. Vincent, and R. K. Stewart. 2001. Body size as an indicator of parasitoid quality in male and female Anagyrus kamali (Hymenoptera: Encyrtidae). Bull. Entomol. Res. 91: 363-367.

Salles, L.A.B. 1992. Metodologia de criação de Anastrepha fraterculus (Wiedmann, 1830) (Diptera: Tephritidae) em dieta artificial em laboratório. Anais da Sociedade Entomológica do Brasil 21: 479-486.

Salles, L.A.B. 1996. Parasitismo de Anastrepha fraterculus (Wied.) (Diptera: Tephritidae) por Hymenoptera, na região de Pelotas, RS. Pesquisa Agropecuária Brasileira 31: $769-744$.
SAS Institute. 2002. User's manual, version 9.2. SAS Institute, Cary, NC

Schliserman, P., S. M. Ovruski, O. R. de Coll, and R. Wharton. 2010. Diversity and abundance of hymenopterous parasitoids associated with Anastrepha fraterculus (Diptera: Tephritidae) in native and exotic host plants in Misiones, Northeastern Argentina. Fla. Entomol. 93: 175-182.

Souza, S.A.S., A.L.S. Resende, P. C. Strikis, J. R. Costa, M.S.F. Ricci, and E. L. Aguiar-Menezes. 2005. Infestação natural de moscas frugívoras (Diptera: Tephritoidea) em café arábica, sob cultivo orgânico arborizado e a pleno sol, em Valença, RJ. Neotropical Entomology 34: 639-648.

Tillman, P. G., and J. R. Cate. 1993. Effect of host size on adult size and sex ratio of Bracon mellitor (Hymenoptera: Braconidae). Environ. Entomol. 22: 1161-1165.

Walder, J.M.M. 2002. Produção de moscas-das-frutas e seu inimigos naturais: associação de moscas estéreis e controle biológico, pp. 181-190. In J.R.P. Parra, P.S.M. Botelho, B. S. Corrêa-Ferreira, and J.M.S. Bento (eds.), Controle Biológico no Brasil: Parasitóides e Predadores. Editora Manole, Barueri, SP, Brazil.

Wharton, R. A., S. Ovruski, and F. E. Gilstrap. 1998. Neotropical Eucoilidae (Cynipoidea) associated with fruitinfesting Tephritidae, with new records from Argentina, Bolivia and Costa Rica. J. Hymenopt. Res. 7: 102-115.

Received 2 April 2013; accepted 20 August 2013 


\section{AUTHOR QUERIES}

\section{AUTHOR PLEASE ANSWER ALL QUERIES}

1-AQ1: This article has been lightly edited for grammar, style, and usage throughout the main text as well as the figure legends and table captions, table bodies, and footnotes, as appropriate. Please limit your corrections to substantive changes that affect meaning. If no change is required in response to a query, please write "OK as set" in the margin. Thank you.

2-AQ2: Per ESA, authority names are not allowed in the article title. Please confirm the changes in the article title and amend if necessary.

3-AQ3: Per style, key words are singular. Please note change made.

4-AQ4: Should the sentence "...we only increased the amount of agar added, from 10 to $3.6 \mathrm{~g}$ " be "...we only increased the amount of agar added, from 3.6 to $10 \mathrm{~g}$ "? Please verify and amend if necessary.

5-AQ5: Please provide Manufacturer details (Manufacturer, Location [city, state, or country]) for Ohaus Explorer SQ17 precision balance.

6-AQ6: Per ESA style, please provide the city and state (or country) for all manufacturers cited in the text (or confirm whether those inserted are correct).

7-AQ7: Please provide the significance of lowercase baseline alphabets in Table 1.

8-AQ8: Please define all acronyms in the Acknowledgments if they are not already defined in the main text.

9-AQ9: Per ESA style, please spell out journal titles in foreign references and verify the ones inserted are spelled out correctly.

10-AQ10: Per ESA style, in Article/Chapter in Book references, Book Title is in cap/lowercase. Please verify that the changes to the Book Titles are correct.

11-AQ11: Please note that the reference "Messing 1993" is not cited in the text. Please cite it in text or delete from the reference list.

12-AQ12: Please provide street address for affiliation 1.

13-AQ13: Please provide department/division name and street address for affiliation 2. 